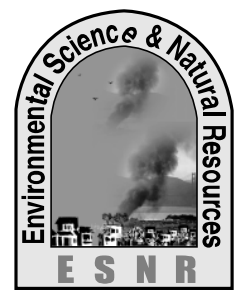

Abstract

J. Environ. Sci. \& Natural Resources, 5(2) : 15 - 21, 2012

ISSN 1999-7361

\title{
Physicochemical Properties and Chemical Constituents of Oil from Joan Seed (Trachyspermum ammi L)
}

\author{
S. Morshed ${ }^{1}$, M. K. Alam ${ }^{2}$, A. Begum ${ }^{3}$, S. M. S. Shahriar ${ }^{1}$, K. N. Sharmin ${ }^{3}$ and \\ S. Akther ${ }^{2}$ \\ ${ }^{1}$ Dept. of Applied Chemistry and Chemical Technology, ${ }^{2}$ Dept. of Food Processing and Engineering, \\ ${ }^{3}$ Dept. of Applied Food Science and Nutrition; \\ Chittagong Veterinary and Animal Sciences University, Chittagong-4202, Bangladesh
} characteristics and fatty acid composition. Oil from carom seed collected from local market was extracted with n-hexane in a glass Soxhlet apparatus. Extracted oil was dark green, burning taste, spicy in odour and soluble in n-hexane, chloroform, pet. ether and benzene. Its chemical characteristic such as acid value (6.69), Iodine value (79.39), Peroxide value (457.11), Saponification value (184.32), Unsaponified matter (9.11), Free fatty acid value as petroselinic acid (48.1) were determined by conventional method. The composition of fatty oil was determined by Gas Liquid Chromatography (GLC). From GLC analysis the main constituents of fatty oil such as Petroselinic acid (89.35\%), Oleic acid (5.86\%), Linoleic acid (4.79\%) were determined. For the better evaluation of these spices, it is necessary to know their complete chemical composition.

Keyword: Trachysprermum ammi (L), Fatty oil, Physicochemical properties, Chemical constituents

\section{Introduction}

Trachyspermum ammi, commonly referred as Bishop's weed, carom seed (English name) and joan in Bengali language, is an erect annual herb with straight stem originated in Persia, India and Bangladesh (Wadikar et al., 2012). Trachyspermum ammi (L) Sprague is a Greek work Trachy = rough and spermum $=$ seeded, whereas ammi is name of plant in Latin. Syn. Carum copticum, commonly known as Joan belonging to family Apiaceae or Umbelliferae (Dwivedi et al., 2012). The plant has a similarity to parsley. Because of their seed-like appearance, the fruit pods are sometimes called seed. They are egg-shaped and greyish. According to Ayurveda, the joan seeds are hot, pungent, stomachic, appetizer, aphrodisiac, carminative, laxative and diuretic. Joan is traditionally used as remedy for gastric disturbances and as a digestive aid. The thymol and carvacrol derivatives and other minor components from joan are responsible for their functional properties (Anilakumar et al., 2009 and Pathak et al., 2010). Some disagreement about the presence of its constituents was observed. Therefore the present work was designed to carry out a total investigation of Joan seed's fatty oil for the purpose to get information for industrial as well as medicinal applications of fatty oil and characterization and identification of the constituents of fatty oil isolated from the seed by GLC.

\section{Materials \& methods}

1. Raw materials: Joan (Trachysprermum ammi) seeds were procured from the local market.

2. Chemicals and reagents: Solvents and chemicals of analytical or reagent grade were used in all experiments unless otherwise stated. Chloroform, acetic acid, acetic anhydride, ether, bromine, ethanol, Pet.ether (b.p. $60-80^{\circ} \mathrm{C}$ ), (sigma E.merck or BDH) were used after distillation. $\mathrm{BF}_{3}-\mathrm{CH}_{3} \mathrm{OH}$ complex and standard methyl esters of fatty acid (LIPID STANDARD) were obtained from E.MERCK and SIGMA, respectively.

3. Gas Liquid Chromatography: Gas liquid chromatography was conducted with a varian gas chromatograph fitted with a flame ionization detector and glass column $(2800 \times 0.2 \mathrm{~cm}$ i.d. $)$. A $3 \% \mathrm{OV}-225$ on gas chrom Q (100/120 mesh) column was used at $200^{\circ} \mathrm{C}$ isotherm with a nitrogen flow of $25 \mathrm{ml}$ per minute.

\section{Investigation of joan seed (Trachyspermum ammi) fatty oil}

\subsection{Extraction of the fatty oil from joan seed}

The fatty oil of sun dried joan seed was extracted with n-hexane (bp $68.2^{\circ} \mathrm{C}$ ) in a glass Soxhlet apparatus.

\subsection{Analysis of the essential oil 4.2.1. Determination of physical properties of joan seed fatty oil}

4.2.1.1. Solubility of fatty oil in different solvent A small amount of fatty oil was taken into a test tube and $3 \mathrm{ml}$ of $\mathrm{n}$-hexane was added to it. Then the clear solution was obtained. Then a small amount of fatty oil was taken into another test tube and $4 \mathrm{ml}$ of benzene solvent was added to it. The solubility of the fatty oil was performed with chloroform and pet. ether (b.p $60-80^{\circ} \mathrm{C}$ ) and clear solution was obtained in each solvent. 


\subsubsection{Determination of chemical properties of joan seed fatty oil}

\subsubsection{Determination of acid value and free fatty} acid

Accurately $0.25 \mathrm{~g}$ of the fat was taken in a flask. Fifty $\mathrm{ml}$ of $95 \%$ ethanol was added into the flask, and the mixture was neutralized with $0.1 \mathrm{~N}$ aqueous alkali using $0.5 \mathrm{ml}$ of the $1 \%$ phenolphthalein indicator. The neutralized ethanol was poured in the flask and mixed the contents of the flask. Then the solution was boiled as hot as possible titration was carried out with $0.1 \mathrm{~N}$ aqueous alkali solutions. The solution was shaked vigorously during the titration. The first appearance of the red coloration that did not fade within $10 \mathrm{sec}$. was considered the end point and the volume of the alkali required were recorded (British Standard Methods of the Analysis of Oils and Fats, 1958).

$$
\begin{aligned}
\text { Acid value } & =\frac{56.1 \times A \times N}{W} \\
\text { Free fatty acid (as petroselinic acid) } & =\frac{2.82 T}{W} \\
\text { Where, } \mathrm{A} & =\text { Volume of the alkali required. } \\
\mathrm{N} & =\text { Normality of the NaOH solution. } \\
\mathrm{W} & =\text { Weight of the sample taken in } \mathrm{g} .
\end{aligned}
$$

\subsubsection{Determination of saponification value}

Accurately weighed $0.26 \mathrm{~g}$ of sample was taken into a round bottomed flask. Twenty five $\mathrm{ml}$ of alcoholic $\mathrm{KOH}$ solution was added into the flask through a pipette taking definite time of draining. Then the flask was boiled continuously for $1 \mathrm{~h}$ under a reflux condenser and swirling the contents of the flask at frequent intervals. The excess alkali was determined while the solution was stilled hot by titration with the $0.5 \mathrm{~N} \mathrm{HCl}$ solution using $0.5 \mathrm{ml}$ of the chosen indicator. Blank determination was carried out with the same $\mathrm{KOH}$ solution at the same time under the same condition (British Standard Methods of the Analysis of Oils and Fats, 1958; Jolly S.C., 1963 and Scott W.W, 1939).

Saponification value $=$-------- $\mathrm{W}$

Where, $\mathrm{N}=$ Normality of $\mathrm{KOH}$ solution.

$$
\mathrm{A}=\text { Volume of } \mathrm{HCl} \text { used (in } \mathrm{ml} \text { ) for the }
$$
sample. titration.

$\mathrm{B}=$ Volume of $\mathrm{HCl}$ used (in ml) for blank

$\mathrm{W}=$ Weight of the sample taken in $\mathrm{g}$.

The equivalent wt. $=$ The molecular wt. of $\mathrm{KOH}=$ 56.1

\subsubsection{Determination of unsaponified matter}

An accurately weighed $0.32 \mathrm{~g}$ of the fatty oil or fat was taken into a $250 \mathrm{ml}$ round bottom flask and $25 \mathrm{ml}$ of alcoholic $\mathrm{KOH}$ was added to it. The flask was attached to a refluxing condenser and heated on a boiling water bath for an hour. The contents of flask were occasionally stirred to mix the solution properly and to ensure complete saponification.

After completion of saponification, the flask was removed from the bath, the condenser was detached and the content of the flask was transferred to a 250 $\mathrm{ml}$ separating funnel. The solution was washed with $50 \mathrm{ml}$ of distilled water. Then the flask was rinsed with $50 \mathrm{ml}$ of pet. ether and this ether was poured cautiously into the separating funnel. The funnel was covered and shaken vigorously while the contents were still slightly warm. After shaking for about 30 seconds the funnel was then suspended and left stationary till there appeared two distinct layers in the liquid mixture. The upper ethereal layer was collected in a round bottom flask by transferring the lower aqueous layer of the solution into another flask. The aqueous layer of the soap solution was extracted twice more with pet. ether in the similar way. The ether extract were then combined $30 \mathrm{ml}$ of distilled water and then $20 \mathrm{ml}$ of $0.5 \mathrm{~N}$ aqueous $\mathrm{KOH}$ solutions.

After one or other of these preliminary treatments, the ethereal solution was washed twice with $20 \mathrm{ml}$ of water. It was shaken vigorously on each occasion. Then successively washed with $20 \mathrm{ml}$ of $0.5 \mathrm{~N}$ aqueous $\mathrm{KOH}$ solutions, $20 \mathrm{ml}$ of distilled water and again with $20 \mathrm{ml}$ of $0.5 \mathrm{~N}$ aqueous $\mathrm{KOH}$ solution and at least twice more with $20 \mathrm{ml}$ of distilled water. Washing was continued with water until the wash water no longer turned pink on addition of phenolphthalein indicator.

The ethereal solution was transferred to a sample flask and ether was evaporated from the solution. Then the flask being almost entirely immersed, hold obliquely and rotated in a boiling water bath. When the flask becomes dried, the contents to constant weight, at the temperature not exceeding $80^{\circ} \mathrm{C}$.

The extract was dissolved in $10 \mathrm{ml}$ of freshly boiled and neutralized $95 \%$ ethanol and titrated with the 0.1 $\mathrm{N}$ alcoholic $\mathrm{NaOH}$ solutions, using phenolphthalein indicator (British Standard Methods of the Analysis of Oils and Fats, 1958 and Hilditch T.P., 1949).

Unsaponified Matter, Percent by Weight = $100 \times W 1$

$W$

Where, $\mathrm{W}_{1}=$ Weight in $\mathrm{g}$ of residue.

$$
\mathrm{W}=\text { Weight in } \mathrm{g} \text { of sample taken. }
$$

\subsubsection{Determination of peroxide value}

Exactly $0.26 \mathrm{~g}$ of sample was placed in a $250 \mathrm{ml}$ glass stoppered conical flask. A $7.5 \mathrm{ml}$ of a mixture of 7.5 $\mathrm{ml}$ of glacial acetic acid and $5 \mathrm{ml}$ of chloroform was added and shaken until the sample was dissolved. Then $0.25 \mathrm{ml}$ of saturated potassium iodide solution was also added to it. The solution had been shaken for at least 1 minute. 
About $15 \mathrm{ml}$ distilled water was added to the solution and it was titrated carefully with $0.05 \mathrm{~N}$ Sodium thiosulphate solutions until the brown color was faded to pale yellow. Five $\mathrm{ml}$ of starch solution was then added and the titration was completed with continuous shaking when the blue color just disappeared at the end point (British Pharmacopaeia: 1998).

Peroxide Value

$=$

$2.6 \times$ strength of $\mathrm{Na2S} 2 \mathrm{O} 3 \times 1000$ Weight of sample in $g$

\subsubsection{Determination of iodine value}

Exactly $0.28 \mathrm{~g}$ of fatty oil was taken in a wellstoppered bottle. The oil was dissolved $10 \mathrm{ml}$ of chloroform. $25 \mathrm{ml}$ of Hanus solution was added to the stoppered bottle from a burette and the solution was allowed to stand for half an hour in dark place with occasional shaking. At the end of this period, $10 \mathrm{ml}$ of KI (15\%) solution was added and shaked thoroughly and $100 \mathrm{ml}$ of distilled water was also added by washing and free iodine on stopper.

The solution was titrated with standard $0.1 \mathrm{~N}$ $\mathrm{Na}_{2} \mathrm{~S}_{2} \mathrm{O}_{3}$ solutions, was added gradually with constant shaking until yellow color of the solution was almost disappeared. A few drops of starch solution were added and the titration was continued until the color was initially disappeared. The blank determination was also carried out observing the same condition omitting the oil (Sidney, Williams, 1984).

(S-B) X N X 12.69

Iodine Value = -------

Where, $\mathrm{S}=$ Volume of $\mathrm{Na}_{2} \mathrm{~S}_{2} \mathrm{O}_{3}$ required for the sample.

$\mathrm{B}=$ Volume of $\mathrm{Na}_{2} \mathrm{~S}_{2} \mathrm{O}_{3}$ required for the blank titration.

$\mathrm{N}=$ Strength of the $\mathrm{Na}_{2} \mathrm{~S}_{2} \mathrm{O}_{3}$ solution.

$\mathrm{G}=\mathrm{Wt}$. of the fatty oil taken in $\mathrm{g}$.

\subsubsection{GLC Analysis of fatty oil}

The fatty oil was analyzed as the methyl ester of their fatty acid contents by GLC. During esterification of fatty oil, glycerides and phospholipids were saponified and fatty acids were liberated and esterified in presence of sodium methoxide.

\subsubsection{Preparation of methyl esters of reference fatty acids}

Reference fatty acids (100 mg of each) were taken in a pear-shaped flask. A condenser was attached with it and refluxed for 10 minutes. Then $5 \mathrm{ml} \mathrm{BF}_{3}-\mathrm{CH}_{3} \mathrm{OH}$ complex was added from a bulb pipette through condenser and continued boiling for 2 minutes. Five $\mathrm{ml}$ of hexane was added through condenser and boiled for another 1 minute. Then hot mixture was poured into a small separating funnel with $10 \mathrm{ml}$ of hexane. Five $\mathrm{ml}$ of distilled water was added to it. The funnel was shaken vigorously and the layers were allowed to separate. The aqueous methanolic layer was drained off and discarded. The hexane layer was dried by treating with anhydrous sodium sulphate, filtered into a quick fit flask, concentrated to a small volume by using vacuum evaporator and transferred to a vial. Finally the hexane containing mixture of methyl ester of acids were concentrated to a few drops by blowing nitrogen gas and stored in a refrigerator before analysis by GLC (AOAC, 1984).

\subsubsection{Preparation of methyl esters of sample fatty acids fraction}

Exactly $0.11 \mathrm{~g}$ of the joan seed fatty acid fraction was taken in a pear-shaped flask. Four $\mathrm{ml}$ of $0.5 \mathrm{~N}$ methanolic $\mathrm{NaOH}$ solution and some boiling chips were added to the sample. A condenser was attached with it and refluxed for 10 minutes. Then $5 \mathrm{ml} \mathrm{BF}_{3}$ $\mathrm{CH}_{3} \mathrm{OH}$ complex was added from a bulb pipette through condenser and continued boiling for 2 minutes. Five $\mathrm{ml}$ of hexane was added through condenser and boiled for another 1 minute. Then hot mixture was poured into a small separating funnel with $10 \mathrm{ml}$ of hexane. Five $\mathrm{ml}$ of distilled water was added to it. The funnel was shaken vigorously and the layers were allowed to separate. The aqueous methanolic layer was drained off and discarded. The hexane layer was dried by treating with anhydrous sodium sulphate, filtered into a quick fit flask, concentrated to a small volume by using vacuum evaporator and transferred to a vial. Finally the hexane containing mixture of methyl ester of acids were concentrated to a few drops by blowing nitrogen gas and stored in a refrigerator before analysis by GLC (AOAC, 1984).

\subsubsection{Determination of fatty acid composition of the fatty oil by gas chromatography}

Methyl ester of fatty acids was diluted to $7 \%$ with nhexane solvent. An inert carrier gas (i.e. nitrogen) was introduced, from a large gas cylinder through the port, the column and the detector. The flow rate of the carrier gas was adjusted to insure reproducible retention times and to minimize detector drift. The sample was injected with the help of a micro syringe through a heated injection part. The injected sample was vaporized and carried into the column. The long tube of the column was tightly packed with solid particles. The solid support was uniformly covered with a thin film of a high boiling liquid (the stationary phase). The sample components were partitioned between the mobile phase and stationary liquid phase and it was separated into its individual components. 
The carrier gas and the sample components were then emerged from the column and passed through the detector. The amount of each component was measured on the basis of its concentration by this device and generated a signal which was registered electrically. This signal passed to a recorder. The methyl esters of the standard reference fatty acids were analyzed by TLC using column packed with silar $10^{\circ} \mathrm{C}$. The reference sample and joan fatty oil sample chromatogram are shown in figure: 2 and figure: 3 respectively (Richard J. Block; Emmett L. Durrum; Gunter Zweig: Paper Chromatography and Paper Electrophoresis, $2^{\text {nd }}$ Ed. Revised and Enlarged).

\subsubsection{Identification}

The methyl ester of fatty acids of Joan seed were identified by comparing the retention time of authentic samples viz resin acid, palmitic acid, petroselenic acid, oleic acid, linolic acid. Furthermore the peaks on the chart were identified with the help of respective chain lengths of different fatty acids. The percentage composition was expressed as weight percent. The fatty acid composition is computed by dividing the corrected peak areas of each peak by sum of the corrected peak areas and multiplying with 100 .

\section{Results and Discussion}

The oil was extracted from the joan seed by solvent extraction method using n-hexane as an extracting solvent in a Soxhlet apparatus. The yield of the oil was found to be $1.43 \%$. The physical characteristics such as color, appearance, taste and solubility of the joan fatty oil were determined by conventional methods. The purified fatty oil was dark green in color. It had burning taste. It appeared as a homogeneous and liquid at room temperature $\left(25^{\circ} \mathrm{C}\right)$. The joan fatty oil is completely soluble in n- hexane, chloroform, pet. ether and benzene (Table 1).

The chemical tests were performed to evaluate the nature of the Joan fatty oil. The values were

Table: 1. Physical characteristic of joan seed fatty oil

\begin{tabular}{|c|l|c|}
\hline Sl. No. & \multicolumn{1}{|c|}{ Characteristics } & Result \\
\hline O1 & Percentage of fatty oil & $1.43 \%$ \\
\hline 02 & Taste & Burning taste \\
\hline 03 & Odor & Spicy \\
\hline 04 & Color & Dark green \\
\hline 05 & Solubility in n-hexane & Soluble \\
\hline 06 & Solubility in chloroform & Soluble \\
\hline 07 & Solubility in pet. ether & Soluble \\
\hline 08 & Solubility in benzene & Soluble \\
\hline
\end{tabular}

expressed in terms of some customary constants. Acid value of this Joan fatty oil was 6.69. This value indicates the proportion of free fatty acid in this particular oil. Saponification value of this Joan fatty oil was found to be 184.33. The iodine value of this oil was found to be 79.39. The unsaponified matter was found to be $9.11 \%$ in this fatty oil sample. The peroxide value of joan fatty oil was found to be $457.11 \%$.

Some characteristics of Joan can be compared with some edible and non-edible fats and oils available in Bangladesh. In the comparison some parameters like iodine value, saponification value and acid value were used. The iodine value showed the presence of moderate unsaturation which was in agreement with physical state of the oil that means the oil is nondrying in nature. It is known that the oils having iodine value less than 95, generally known as nondrying oil. The other hand Joan seed fatty oil has lower acid value. Lower acid value indicates its ability to be considered as edible oil. The fatty acids composition of joan seed fatty oil can also be compared with some edible and non-edible fats or oils. The fatty acid composition of joan seed oil was determined by Gas Liquid Chromatography (GLC). GLC analysis of the fatty oil revealed that the chromatogram has three peaks assigned to the above acids. From the chromatogram, retention time and peak area of Petroselinic acid, Oleic acid, Linoleic acids were studied and the relative percentage of fatty acid in joan fatty oil calculated. The mole percentages of the individual acids were found Petroselinic acid $(89.35 \%)$, Oleic acid (5.86\%), Linoleic acid (4.79\%). Menon et al. was determined the fatty acid composition of joan fatty oil by ester fractionation and found Palmitic acid (2.6\%), Petroselinic acid (41.8\%), Oleic acid (34.8\%) and Lenoleic acid $(20.7 \%)$ by weight (Menon et al., 1953). The mole percentages of joan fatty acid of Menon et al. findings differs from our findings may be the area, nature of joan seed.

Table: 2. Chemical characteristic of joan seed fatty oil

\begin{tabular}{|c|l|c|}
\hline Sl. No. & \multicolumn{1}{|c|}{ Characteristics } & Result (\%) \\
\hline 01 & Acid value & 6.69 \\
\hline 02 & Iodine value & 79.39 \\
\hline 03 & Peroxide value & 457.11 \\
\hline 04 & Saponification value & 184.32 \\
\hline 05 & Unsaponified matter & 9.11 \\
\hline 06 & $\begin{array}{l}\text { Free fatty acid value as } \\
\text { petroselinic acid }\end{array}$ & 48.1 \\
\hline
\end{tabular}


Table: 3. GLC experimental results of fatty acid composition: (Joan Seed)

\begin{tabular}{|c|c|c|c|l|}
\hline Sl. No. & Retention time & Peak area & Relative percentage & \multicolumn{1}{|c|}{ Remarks } \\
\hline 01 & 3.29 & 2484 & 5.86 & Oleic acid \\
\hline 02 & 16.28 & 37895 & 89.35 & Petroselinic acid \\
\hline 03 & 22.48 & 2031 & 4.79 & Linoleic acid \\
\hline
\end{tabular}
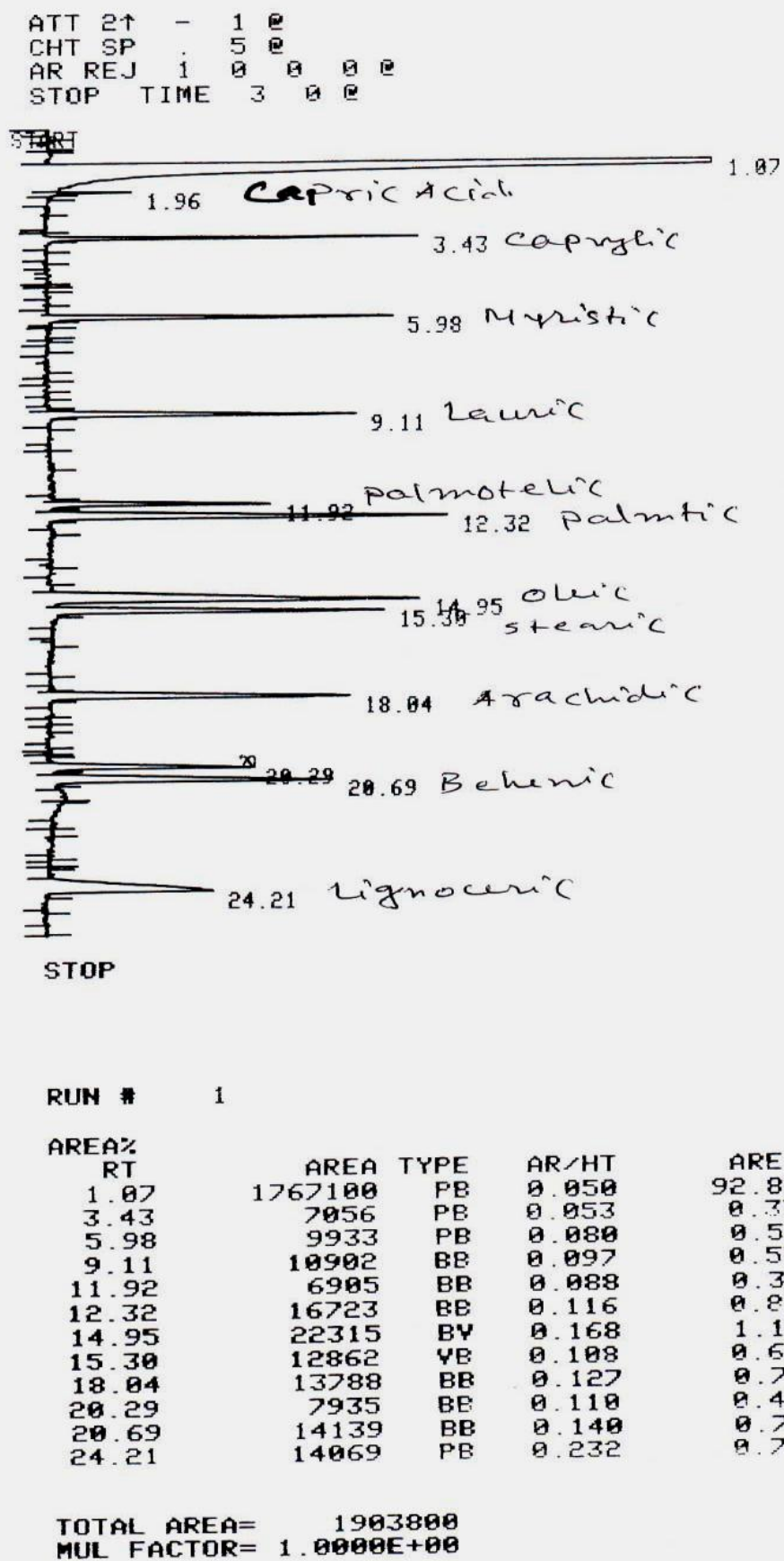

Fig: 1. GLC Chromatogram of reference sample. 

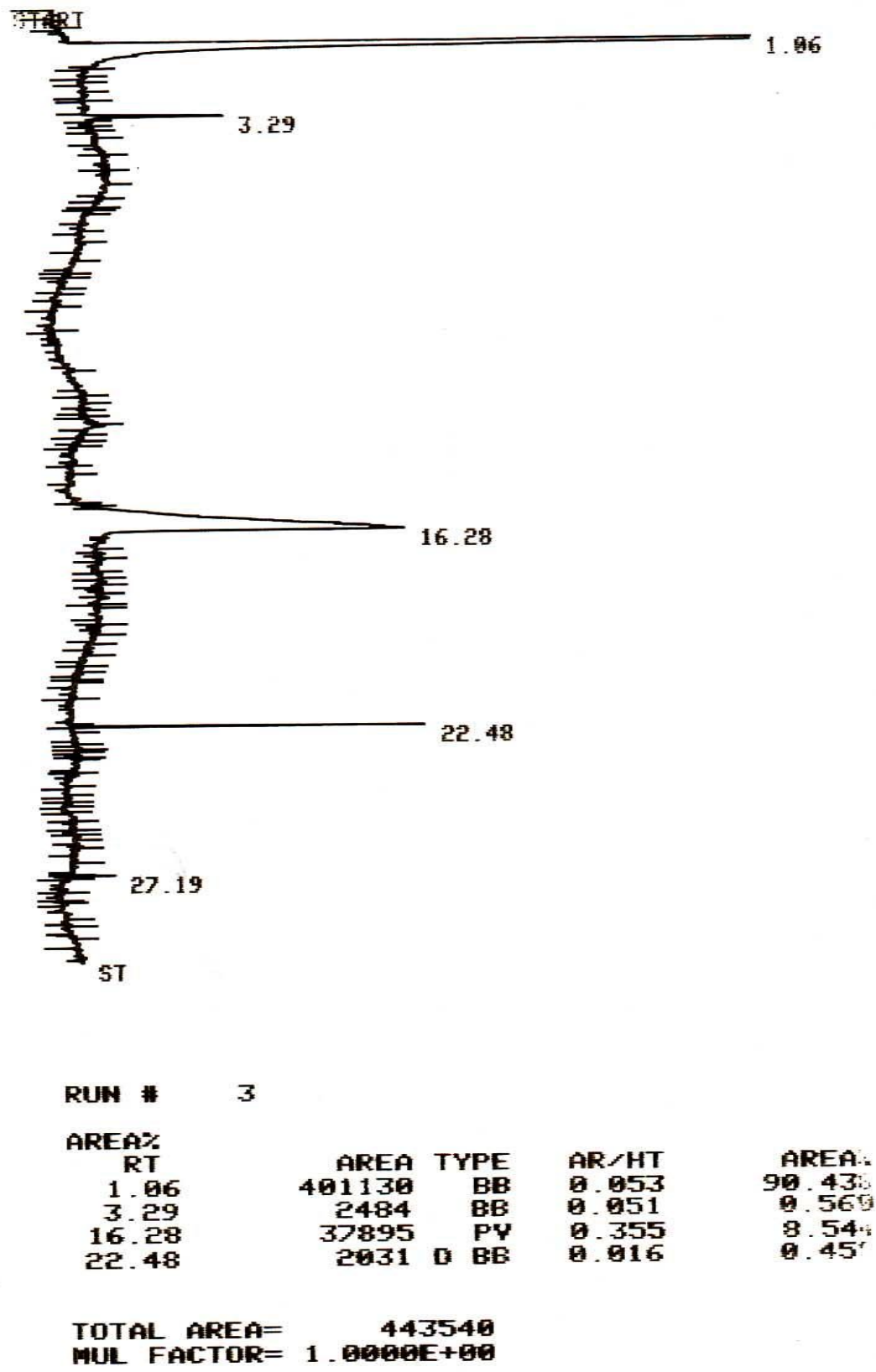

Fig: 2. GLC Chromatogram of the fatty oil of joan seed. 


\section{Conclusion}

The present work therefore, aims to complete chemical investigation of joan seed with particular emphasis on determination of fatty oil. The present investigation has the following steps:

a. Extraction of fatty oil from residue after steam distillation.

b. Characteristic of physical and chemical properties of fatty oil.

c. Investigation of chemical constituents of joan fatty oil.

In the light of above findings obtained from the investigation it is revealed that the joan seed which is now being in cultivated in country, owing to its fatty oil and other valuable nutrients could be used for large scale production of these products. After meeting the internal demand of these products, the remaining amount can earn a considerable amount of foreign exchange through export.

\section{References}

Anilakumar, K. R.; Saritha, V.; Farhat, k. and Bawa, A. S. 2009. Ameliorative effects of Ajwain extract on hexachlorocyclohexane-induced lipid peroxidation in rat liver. Food and Chem. Toxicology, 47: 279-282.

British Pharmacopaeia, 1998. Appendix XF A173 pp.

British Standard Methods of the Analysis of Oils and Fats, 1958, B. S. 684. British Standard Institution Incorporated by Royal Charter. British Standards House, 2 park ST, London, W. I.

Dwivedi, S. N.; Mishra, R. P. and Sangeeta Alava. 2012. Phytochemistry, pharmacological studies and traditional benefits of Trachyspermum ammi (Linn.) Sprague. International Journal of Pharmacy and Life Sciences, 3(5): 17051709

Hilditch, T. P. 1949. Industrial Chemistry of Fats and Waxes, Bailliere lindall \& Cox, London, UK, 39, 41, 47 pp.

Jolly, S. C. 1963. Official Standardized and Recommended Methods of Analysis, 79-94 pp.

Menon, B. K. and Raman, P. S. 1953. Petroselinic acid: Occurrence in some Umbelliferae seed fats. Journal of Ernakulam and Madras University, 3: 128-131.

Official Methods of Analysis of the Association of Official Analytical Chemistry, Washington, 1984.

Pathak, A. K.; Nainwal, N.; Goyal, B. M.; Singh, V.; Nayak, S.; Bansal, P. and Gupta, V. 2010. Pharmacological activity of Trachyspermum ammi: A review. Journal of Pharmacology Research, 3: 895-899

Block, R. J.; Durrum, E. L. and Zweig, G. Paper Chromatography and Paper Electrophoresis, $2^{\text {nd }}$ Ed. Revised and Enlarged.

Scott, W. W.1939. Standard Method of Analysis, 2: 1701-1805 pp.

Williams, S. 1984. AOAC, $14^{\text {th }}$ Ed. 503-532 pp.

Wadikar, D. D. and Premavalli, K. S. 2012. Ajowan (Trachyspermum ammi) munch: A shelf stable ready-to-eat appetizer; its development and storage. International Food Research Journal, 19 (1): 321-325 